Sammlung Metzler Band 153 


\author{
Ronald Schneider
}

\title{
Annette von Droste-Hülshoff
}

2., vollständig neu bearbeitete Auflage

Verlag J.B. Metzler

Stuttgart - Weimar 
Die Deutsche Bibliothek - CIP-Einheitsaufnahme

Schneider, Ronald:

Annette von Droste-Hülshoff / Ronald Schneider.

- 2., vollst. neu bearb. Aufl.

- Stuttgart ; Weimar : Metzler, 1995

(Sammlung Metzler ; Bd. 153)

ISBN 3-476-12153-4

NE: GT

\author{
ISBN 978-3-476-12153-0 \\ ISBN 978-3-476-04088-6 (eBook) \\ DOI 10.1007/978-3-476-04088-6 \\ ISSN 05583667
}

SM 153

Dieses Werk einschließlich aller seiner Teile ist urheberrechtlich geschützt. Jede Verwertung außerhalb der engen Grenzen des

Urheberrechtsgesetzes ist ohne Zustimmung des Verlages unzulässig und strafbar. Das gilt insbesondere für

Vervielfältigungen, Übersetzungen, Mikroverfilmungen und die Einspeicherung und Verarbeitung in elektronischen Systemen.

(C) 1995 Springer-Verlag GmbH Deutschland

Ursprünglich erschienen bei J.B. Metzlersche Verlagsbuchhandlung und Carl Ernst Poeschel Verlag GmbH in Stuttgart 1995

EIN VERLAG DER SPEKTRUM FACHVERLAGE GMBH 


\section{Inhalt}

Vorwort zur 2. Auflage ………………………......................... VII

Abkürzungsverzeichnis ............................................................... IX

1. Grundlagen der Textinterpretation: Editionen, Handschriften, Bibliographien, Forschungsberichte und monographische Darstellungen ...................................... 1

1.1 Textausgaben und Textgrundlagen ................................... 1

1.2 Bibliographien und Forschungsberichte ......................... 7

1.3 Monographische Darstellungen zu Leben und Werk ...... 8

2. Weltbild und dichterisches Selbstverständnis

der Droste im geschichtlichen Kontext ............................. 14

2.1 Die »Restaurationszeit« als dialektischer

Epochenbegriff .............................................................. 14

2.2 Das Weltbild der Droste und sein ideologischer Ort .... 17

2.3 Poetologische Grundlagen und Voraussetzungen ........... 20

2.4 Traditionsbezüge ............................................................. 23

3. Biographische Voraussetzungen ...................................... 26

3.1 Forschungsstand ...................................................... 26

3.2 Herkunft und Persönlichkeitsbild der Droste ................ 28

$3.3 \quad$ Freundschaften .............................................................. 31

4. Das Jugendwerk .................................................................. 38

4.1 Forschungsstand .......................................................... 38

4.2 Bertha oder die Alpen ..................................................... 39

4.3 . Walther .................................................................. 40

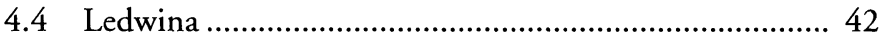

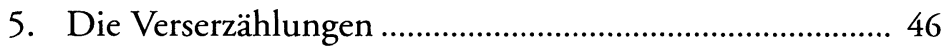

5.1 Das Hospiz auf dem großen St. Bernhard ..................... 47

5.2 Des Arztes Vermächtnis ................................................ 52

5.3 Die Schlacht im Loener Bruch. 1623 ............................ 60

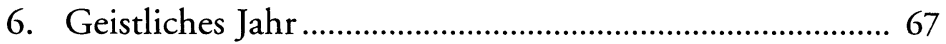




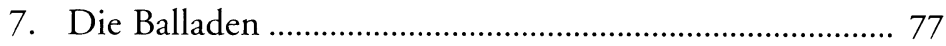

7.1 Textgrundlagen und Entstehung...................................... 77

7.2 Zur Forschungslage .................................................... 78

7.3 Grundstrukturen und Typologie des Balladenwerkes .... 80

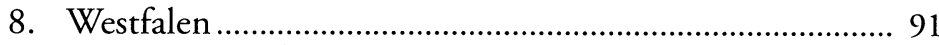

8.1 Das Westfalen-Projekt der Droste ................................. 91

8.2 Friedrich Mergel, eine Criminalgeschichte des 18ten Jahrhunderts ................................................... 95

8.3 Bei uns zu Lande auf dem Lande ................................ 95

8.4 Westphälische Schilderungen (= Bilder aus Westfalen) ... 98

8.5 Die Judenbuche ........................................................ 101

9. Der SPIRITUS FAMILIARIS - Joseph - Perdu! ............. 109

9.1 Der SPIRITUS FAMILIARIS des Roßtäuschers ............ 109

9.2 Joseph …………………………………………......... 115

9.3 PERDU! ............................................................. 117

10. Das lyrische Werk .......................................................... 121

10.1 Lyrik im Biedermeier ............................................... 121

10.2 Textgrundlagen ......................................................... 123

10.3 Forschungsstand ………………………………....... 125

10.4 Zeitkritische »Tendenzlyrik" ...................................... 129

10.5 Genrebilder und erzählende Gedichte ....................... 132

10.6 Naturlyrik ................................................................... 134

10.7 Persönliche Lyrik ......................................................... 137

10.8 Gelegenheitslyrik ....................................................... 142

11. Zur Wirkungsgeschichte der Droste .................................. 145

11.1 Methodologische Vorüberlegungen und Forschungsstand ................................................ 145

11.2 Die Publikumsresonanz von 1838 bis zur Jahrhundertmitte ………………………………....... 147

11.3 Zwei Jahrzehnte intensiver Publizitätsbemühungen und Editionsarbeit (1850-1870) ................................. 149

11.4 Der literarische Durchbruch und seine Bedingungsfaktoren (1870-1900) …………………………...... 152

11.5 Droste-Rezeption im 20. Jahrhundert ........................ 158

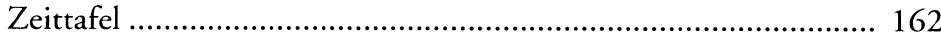

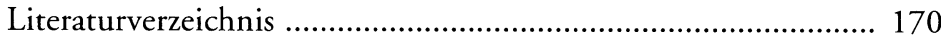

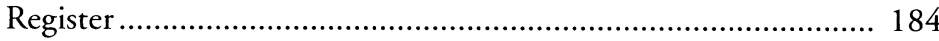

Angaben zum Autor ………………………………................ 187 


\section{Vorwort zur 2. Auflage}

Die erste Auflage dieses Metzler-Bandes erschien 1977. In ihm wurde der Forschungsertrag der Droste-Philologie überwiegend negativ bilanziert und abschließend (im Grundlagenkapitel) konstatiert: "Weder liegt eine in Textkritik und Kommentar allen Ansprüchen des gegenwärtigen Forschungsstandes genügende Edition von Werk und Briefen der Droste vor, noch existiert eine verläßliche, quellenkritisch erarbeitete und sinnvoll akzentuierende Biographie, noch eine detailliert und verläßlich informierende Werkmonographie." Heute, nach 18 Jahren Forschungsfortgang, hat sich diese Bilanz erfreulicherweise erheblich aufgehellt.

Für die 2. Auflage hatte dies zur Konsequenz, daß der Band grundlegend überarbeitet, erweitert und ergänzt werden mußte, unter anderem um ein ganz neu geschriebenes Kapitel zur Rezeptionsgeschichte. Der Aufbau und die grundlegende Konzeption des Bandes konnte dagegen unverändert gelassen werden, da mir die dahinter stehenden Uberlegungen und Argumente nach wie vor gültig erscheinen.

Der Band will zunächst - entsprechend der Konzeption der Realien-Reihe - in den aktuellen Forschungsstand einführen und die Grundlagen für ein angemessenes Verständnis von Werk und Autorin legen. Besondere Berücksichtigung findet dabei der literarhistorische Kontext, da das Werk der Droste in Monographien und Interpretationen noch immer viel zu oft aus seinem historischen, geistesgeschichtlichen und poetologischen Bezugshorizont herausgelöst und in seinen literarischen und wirkungsästhetischen Intentionen entsprechend verfehlt wird. Der außergewöhnlich heterogene wissenschaftliche Droste-Diskurs macht es überdies immer wieder notwendig, isolierte Positionen und konträre Ansätze dialogisch miteinander zu verknüpfen und - wo möglich - synthetisch zusammenzuführen, vor allem bei den viel interpretierten Texten und hier allem voran bei der Judenbuche.

Die Droste hat ein in vieler Hinsicht schwieriges, komplexes und sperriges Werk hinterlassen, das der Rezeption oft erheblichen Widerstand entgegensetzt. Der Band ist daher bemüht, auch interpretatorisch an die Texte heranzuführen, wobei auch von der Möglichkeit Gebrauch gemacht wird, Textausschnitte in den Blick zu rükken. In diesen interpretatorischen Passagen greife ich überall dort, 
wo die Forschungslage dünn, problematisch oder unergiebig ist vor allem beim Jugendwerk, den Versepen und bei Teilbereichen der Prosa und des lyrischen Werkes - auf eigene Untersuchungen und Publikationen zurück.

Detaillierter als sonst in dieser Reihe üblich ist im Anhang die Zeittafel erstellt. Dies begründet sich einerseits darin, daß eine verläßlich informierende Biographie noch immer eines der dringendsten Desiderate der Droste-Forschung ist. Andererseits ist mit der sorgfältig recherchierten, aber nur beschwerlich zu lesenden DrosteChronik Walter Göddens (1994) inzwischen eine Faktenbasis erstellt, die vieles präzisiert und eine ganze Reihe bislang in der Droste-Literatur tradierter Daten und Fakten korrigiert. Diese Chronik ist der Zeittafel zugrunde gelegt.

Danken möchte ich all denen, die meine Arbeit an der 2. Auflage des Bandes begleitet haben. Im besonderen danke ich Frau Dipl.Bibl. Marianne Müller, Solingen, Frau Dipl.-Bibl. Anja Krokowski und Bibl.-Ass. Heike Rennscheidt, Oberhausen, für bibliographische Recherchen und Literaturvermittlung. Herrn Prof. Dr. Wilhelm Kühlmann, Heidelberg, danke ich für vielfältige Anregungen und Hinweise. Ich danke Frau Gerlinde Nelles für die Mitarbeit am Literaturverzeichnis und am Register und meiner Lebensgefährtin, Frau Monika Boyen, die nicht nur das Manuskript erstellt, sondern die gesamte Arbeit kritisch begleitet und inhaltlich ergänzt hat. Ihr ist dieser Band gewidmet.

Oberhausen, im Februar 1995

Ronald Schneider 


\section{Abkürzungsverzeichnis}

$\mathrm{AvDH}$

Beitr.

DJ

DU

DVjs

EG

Euph.

GLL

GRM

GQ

$\mathrm{H}$

HKA

$\mathrm{HZ}$

$\mathrm{JbFDH}$

JDG

JEGPh

Annette von Droste-Hülshoff

Kleine Beiträge zur Droste-Forschung (ab Nr. 4: Beiträge zur Droste-Forschung), hrsg. v. Winfried Woesler, 1971-1982

Droste-Jahrbuch, hrsg. v. Clemens Heselhaus und Winfried Woesler, $1987 \mathrm{ff}$.

Der Deutschunterricht

Deutsche Vierteljahresschrift für Literaturwissenschaft und Geistesgeschichte

Etudes Germaniques

Euphorion

German Life \& Letters

Germanisch-romanische Monatsschrift

The German Quaterly

Annette von Droste-Hülshoff. Sämtliche Werke, hrsg., in zeitlicher Folge geordnet und mit Nachwort und Erläuterungen versehen v. Clemens Heselhaus, München 1952 (7. Aufl. 1974; Zitate nach der 5. Aufl., München 1966)

Annette von Droste-Hülshoff. Historisch-kritische Ausgabe. Werke, Briefwechsel, hrsg. v. Winfried Woesler, Tübingen $1978 f f$.

Historische Zeitschrift

Jahrbuch des Freien Deutschen Hochstifts

Jahrbuch der Droste-Gesellschaft, hrsg. v. Clemens Heselhaus. 1947-1972

Journal of English and Germanic Philology 
Der Freiin Annette Elisabeth von Droste-Hülshoff Gesammelte Werke, hrsg. v. Elisabeth Freiin von Droste-Hülshoff. Nach dem handschriftlichen Nachlaß verglichen und ergänzt, mit Biographie, Einleitungen und Anmerkungen versehen von Wilhelm Kreiten, Bd. 1-4, Münster und Paderborn 18841887 (2. Aufl. Paderborn 1900-1906)

Modellfall der Rezeptionsforschung. Droste-Rezeption im 19. Jahrhundert. Dokumentation, Analysen, Bibliographie, hrsg. v. Winfried Woesler. Erstellt in Zusammenarbeit mit Aloys Haverbusch und Lothar Jordan, Bd. 1-2 in 3, Frankfurt/Main [u.a.] 1980

Annette von Droste-Hülshoff: Sämtliche Werke in zwei Bänden, hrsg. v. Bodo Plachta und Winfried Woesler, Frankfurt/Main 1994

SKB

Die Briefe der Annette von Droste-Hülshoff. Gesamtausgabe, hrsg. v. Karl Schulte Kemminghausen, 2 Bd., Jena 1944 (Unveränderter Nachdruck: Darmstadt 1968)

SKW

Annette von Droste-Hülshoff: Sämtliche Werke. In Verbindung mit Bertha Badt und Kurt Pinthus hrsg. v. Karl Schulte Kemminghausen, Bd. 1-4 in 6, München 1925-1930

W

Annette von Droste-Hülshoff: Sämtliche Werke. Nach dem Text der Originaldrucke und der Handschriften, hrsg. v. Günther Weydt und Winfried Woesler, Bd. 1: München 1973, Bd. 2: München 1978 (zuletzt Bd. 1 in 3. Aufl. 1989 und Bd. 2 in 2. Aufl. 1989; Zitate nach der 1. Aufl.)

WW Wirkendes Wort

$\mathrm{ZfdPh} \quad$ Zeitschrift für deutsche Philologie 